\title{
Clinical presentation, growth, and pubertal development in Addison's disease
}

\author{
D B GRANT, N D BARNES, M W MONCRIEFF, AND M O SAVAGE \\ Hospital for Sick Children, Great Ormond Street, London, Addenbrookes Hospital, Cambridge, John \\ Radcliffe Hospital, Oxford, and Queen Elizabeth Hospital for Children, London
}

SUMmaRY The clinical course of eight boys and six girls with Addison's disease has been reviewed. Adrenal antibodies were found in five boys and five girls, and four children showed clinical evidence of other autoimmune disease (hypoparathyroidism (three); diabetes (one)). The presentation was insidious in 12 children but acute in two. On treatment, linear growth was normal and, with the exception of one girl with theca cell antibodies, pubertal development proceeded normally in the older patients.

Chronic adrenal failure-Addison's disease-is rare in childhood and few series have been reported. Standard texts give little information on the presentation and clinical course of the disease in childhood, and conclusions are sometimes based on single case reports. We report 14 children with Addison's disease treated personally, and define the aetiology, clinical presentation, and outlook for growth and puberty.

\section{Patients}

We have reviewed the records of 24 children with chronic adrenal insufficiency who have been under our care: none had neurological symptoms suggesting the presence of leucodystrophy (AddisonSchilder disease). In three boys there was a history of adrenal insufficiency in a brother or maternal male cousin. These patients almost certainly had X linked familial adrenal hypoplasia and have been excluded as they do not show spontaneous pubertal development as a result of gonadotrophin deficiency. ${ }^{12}$ Five further children, including two brothers and a brother and sister, presented with noticeable pigmentation and hypoglycaemia. Investigations showed that cortisol secretion was impaired but sodium homeostasis was normal in these five, indicating that they had 'isolated glucocorticoid deficiency ${ }^{34}$; they have also been excluded.

Eight boys and six girls had evidence of both glucocorticoid and mineralocorticoid deficiency, and form the basis of this report. Their ages ranged from $3 \cdot 1$ to $13 \cdot 4$ years at the time of diagnosis and 10 were aged $16 \cdot 0$ to $18 \cdot 5$ years when follow up stopped. Their clinical features are summarised in the Table.

Presenting symptoms. Lethargy (seven cases), skin pigmentation (seven), vomiting (six), and salt craving (four) were the commonest presenting symptoms, and were noted in five boys and four girls. Polyuria due to diabetes mellitus precipitated hospital admission in one of these boys. Two boys presented as acute medical emergencies with sudden collapse after minor respiratory infections. In two girls hypocalcaemic convulsions due to hypoparathyroidism and moniliasis of the mouth and nails preceded symptoms of adrenal insufficiency. Photophobia due to keratitis was the first symptom in a boy who subsequently developed hypoparathyroidism and then adrenal failure.

Laboratory investigations. The results of tests of adrenal function are summarised in the Table. The clinical diagnosis of Addison's disease was confirmed in all but one of the patients by the presence of an inadequate plasma cortisol response to corticotrophin or tetracosactrin stimulation ${ }^{5}$; resting plasma cortisol concentrations were low in some, but not all, cases. Plasma adrenocorticotrophic hormone was raised appreciably in the eight patients investigated. Ten of the patients had documented hyponatraemia, and in four the diagnosis of impaired sodium homeostasis was made on the basis of raised plasma renin activity. ${ }^{6}$ 
Table Clinical features, biochemical findings and tissue antibody results in 14 patients with adrenal insufficiency

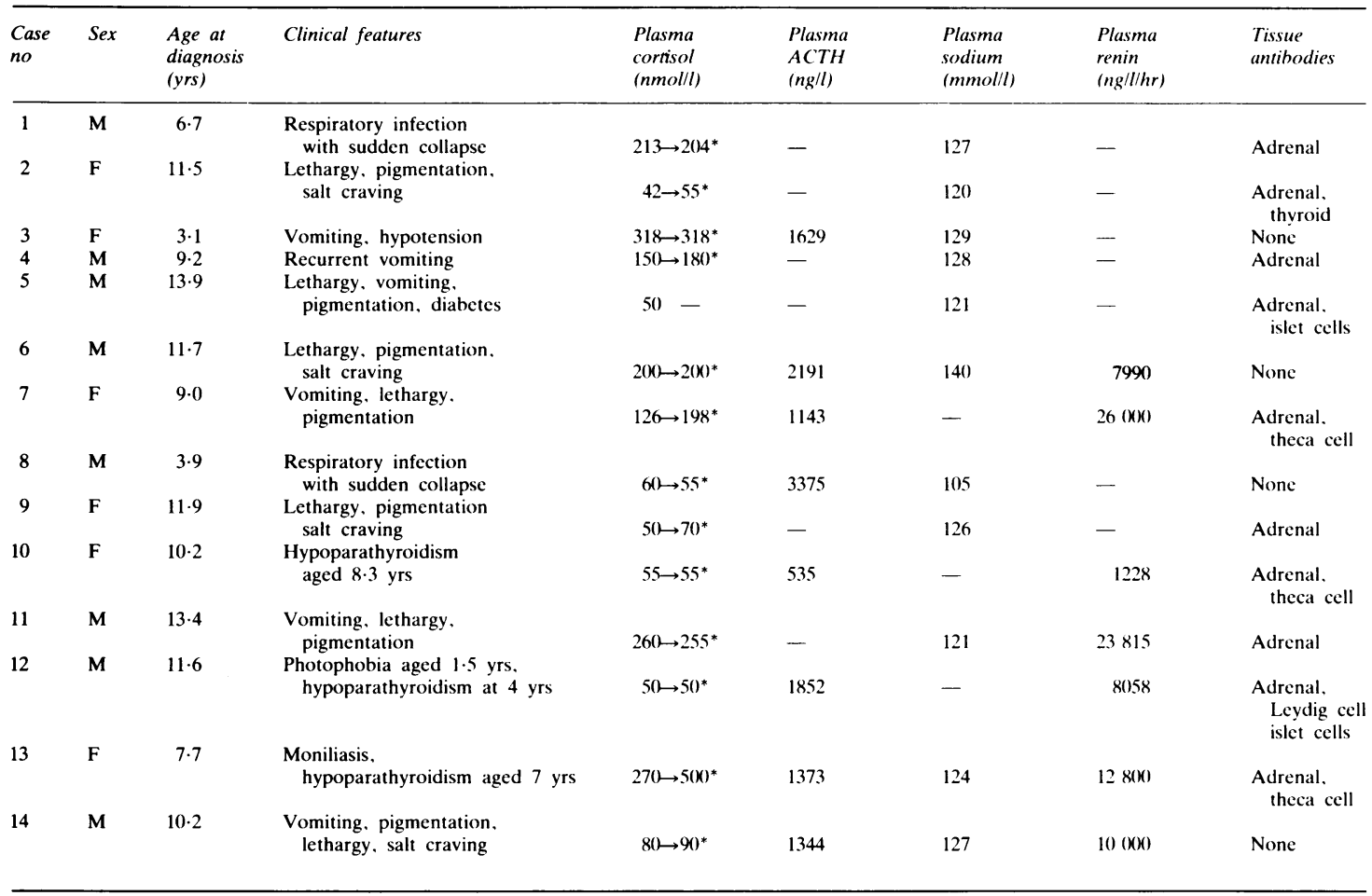

* Cortisol values obtained before and after injection of tetracosactrin or adrenocorticotrophic hormone (ACTH).

The results of tissue antibody studies are also given in the Table. Five girls and five boys had positive antibody titres to adrenal steroid cells. In three girls and one boy there were also positive antibody titres to theca/Leydig cells of the ovary or testis; three of these patients also had hypoparathyroidism. One boy was diabetic and had a combination of adrenal and islet cell antibodies, as did another boy without diabetes. One girl had a combination of adrenal and thyroid antibodies. Three boys and one girl had no detectable tissue autoantibodies; none had a positive tuberculin test or evidence of tuberculosis on chest radiograph, or adrenal calcification on abdominal radiograph.

Growth and pubertal development. The growth patterns of these children are shown in the Figure. With two exceptions, the patients were below average height at the time of diagnosis but only one patient, a boy with hypoparathyroidism and keratitis, was below the 3rd centile. While growth rates on treatment were generally normal, only one patient achieved an adult height above the 50th centile.
One of the girls with both adrenal and theca cell antibodies showed breast development at 14.3 years of age but had not menstruated by the age of $16 \cdot 3$ years: she had raised basal plasma follicle stimulating hormone values. Another girl began breast development at 13.2 years and reached menarche at 15.3 years, and one is still prepubertal at the age of 11.4 years. Two girls with adrenal antibodies but no ovarian antibodies reached menarche at the ages of $12 \cdot 3$ and 13 years.

The one boy with both adrenal and Leydig cell antibodies is still prepubertal at the age of 12.9 years, and another with adrenal antibodies only has just started puberty at the age of $16 \cdot 2$ years. The three other boys with adrenal antibodies were considered to be fully mature at ages of 14.6 to 16 years.

The one girl with persistently negative adrenal antibody titres began menstruation at the age of 15 years. One of the three boys with negative adrenal antibody titres is still prepubertal at the age of 10.9 years, one has just started pubertal development at the age of 16 years, and in one development was complete by the age of 14 years. 

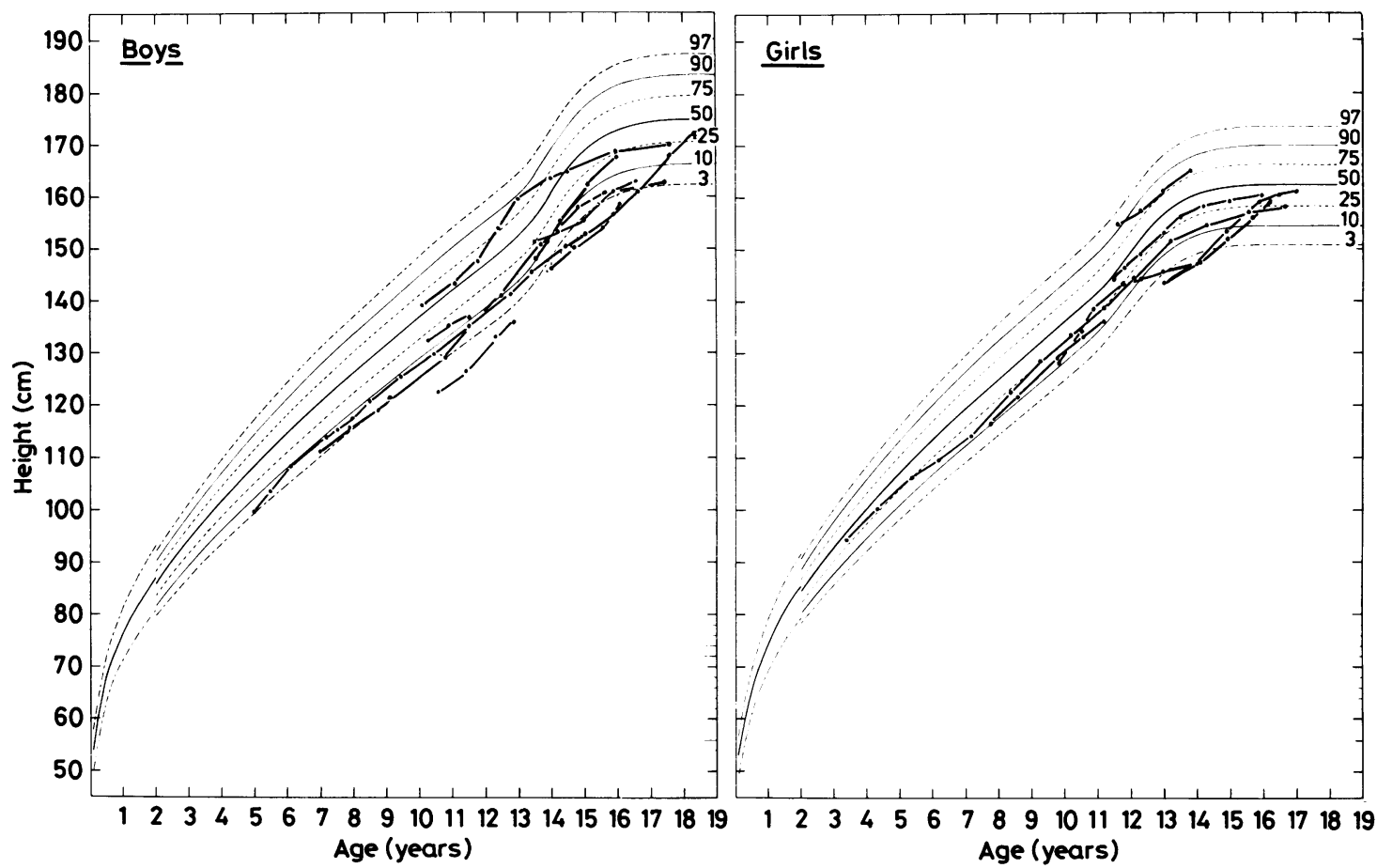

Figure Growth patterns in eight boys and six girls during treatment for adrenal insufficiency.

Treatment. The patients were treated with either cortisone acetate or hydrocortisone together with fludrocortisone, but full details of steroid dosage are only available in six boys and four girls. In general, the lowest dose of steroid that would permit normal health and physical activity with some reduction in skin pigmentation was used. Four of the children were treated with cortisone acetate at an average daily dose of $23.6 \mathrm{mg} / \mathrm{m}^{2}$ (range 13.9 to $31.2 \mathrm{mg} / \mathrm{m}^{2}$ ); six were given hydrocortisone at an average daily dose of $13.8 \mathrm{mg} / \mathrm{m}^{2}$ (range 9.3 to $20.0 \mathrm{mg} / \mathrm{m}^{2}$ ). Fludrocortisone was given at a dose of 0.05 to $0 \cdot 15 \mathrm{mg}$ daily.

\section{Discussion}

Autoimmune disease has been recognised for many years as the commonest cause of adrenal failure in children, and in one large series 19 of 47 children were found to have adrenal antibodies. ${ }^{7}$ In our own smaller series of patients, autoimmune disease was also the commonest cause, adrenal antibodies being found in 10 of 14 . These patients often have other autoimmune disorders, hypoparathyroidism being the most common in our experience. Antibodies against other tissues may be present without any evidence of overt disease, theca/Leydig cell antibodies being found in four of our patients. This autoimmune endocrinopathy is often familial, and it is of interest that the father of one of our patients had developed Addison's disease 14 years earlier.

Tuberculosis is now a very rare cause of Addison's disease in this country, and excluding AddisonSchilder disease, the most likely cause in patients without positive antibody titres is familial adrenal hypoplasia, inherited as an X linked, or less commonly, a recessive disorder. At present the diagnosis of familial adrenal hypoplasia may only be made if a sibling or male cousin has been found to have adrenal insufficiency. Such cases were not included in our study because of the known association with gonadotrophin deficiency, but obviously the absence of a positive family history does not completely exclude this diagnosis. In four patients without adrenal antibodies there was no evidence of tuberculosis or adrenal calcification and the aetiology of the adrenal failure is unknown.

The initial symptoms of Addison's disease are often vague and non-specific, which accounts for the fact that there was considerable delay in making the diagnosis in several of our patients. It is of interest, however, that the two boys who presented with a 
fulminating illness had not had any previous symptoms suggesting the presence of adrenal insufficiency. Symptomatic hypoglycaemia was surprisingly uncommon, although it is a prominent feature in patients with isolated glucocorticoid deficiency. ${ }^{4}$ Skin pigmentation, a well recognised feature, was present at diagnosis in half our patients. Salt craving should also suggest the diagnosis. Loss of weight, a common feature in adults, ${ }^{8}$ was not recorded in our patients, but many of them gained weight rapidly during the early weeks of treatment.

In general, linear growth seems to be normal in adequately treated Addison's disease. The heights of all but one patient were below average, however, at the time of diagnosis, and only one achieved an adult height above the 50th centile. Lack of information on parental height precludes any conclusions as to whether these growth patterns were related to adrenal insufficiency or whether they were largely inherited characteristics. The main risk of steroid treatment is overdosage, causing growth retardation. Most of our patients required relatively low doses of steroids to allow normal health and physical activity, and the average dose of hydrocortisone used in our series was very similar to the cortisol production rate in healthy children. ${ }^{9}$

The above findings confirm that pubertal development is relatively normal in Addison's disease, ${ }^{10}{ }^{11}$ in complete contrast to the delayed puberty due to gonadotrophin deficiency that is a feature of familial adrenal hypoplasia. Spontaneous pubertal development occurred in all our older patients but was very delayed in two boys, one with and one without adrenal antibodies. With the exception of one girl with adrenal and theca cell antibodies who also had raised plasma follicle stimulating hormone concentrations, the older girls achieved menarche at appropriate ages. Whether they will go on to develop ovarian failure with secondary amenorrhoea ${ }^{12}$ remains to be seen.
We thank Professor Deborah Doniach and Dr F Bottazzo for the tissue antibody results and $\operatorname{Dr} M$ Dillon for the plasma renin activity estimations.

\section{References}

' Prader A, Zachmann M, Illig R. Lutcinizing hormone deficiency in hereditary congenital adrenal hypoplasia. J Pediatr 1975;86:421-2.

${ }^{2}$ Hay ID, Smail PJ, Forsyth CC. Familial cytomegalic adrenocortical hypoplasia: an X-linked syndrome of pubertal failure. Arch Dis Child 1981;56:715-21.

${ }^{3}$ Kelch RP, Kaplan SL. Biglieri EG, Danicls DH, Epstein CJ. Grumbach MM. Hereditary adrenocortical unresponsiveness to adrenocorticotropic hormone. J Pediatr 1972;81:726-36.

4 Moshang T, Rosenficid RL, Bongiovanni AM, Parks JS, Amrhein JA. Familial glucocorticoid insufficiency. J Pediatr 1973;82:821-6.

5 Barnes ND, Joseph JM, Atherden SM, Clayton BE. Functional tests of adrenal axis in children with measurement of plasma cortisol by competitive protein binding. Arch Dis Child 1972;47:66-73.

${ }^{6}$ Dillon MJ, Ryness J. Plasma renin activity and aldosterone concentration in children. $B r$ Med $J$ 1975;iv:316-9.

${ }^{7}$ Blizzard RM, Chee D, Davis W. The incidence of adrenal and other antibodies in the sera of patients with idiopathic adrenal insufficiency (Addison's disease). Clin Exp Immunol 1967;2: 19-31.

${ }^{8}$ Nerup J. Addison's disease:-clinical studies. A report of 108 cases. Acta Endocrinol 1974;76:127-41.

${ }^{9}$ Kenny FM. Preeyasombat C. Migeon CJ. Cortisol production rate II. Normal infants, children and adults. Pediatrics 1966:37:34-42.

16 Urban MD, Lee PA, Gutai JP, Migeon CJ. Androgens in pubertal males with Addison's disease. J Clin Endocrinol Metab 1980;51:925-9.

"Lucky AW, Rebar RW, Blizzard RM, Goven EM. Pubertal progression in the presence of elevated serum gonadotropins in girls with multiple endocrine deficiencies. J Clin Endocrinol Metab 1977;45:673-8.

12 Irvine WJ, Chan MMW, Scarth L, et al. Immunological aspects of premature ovarian failure associated with idiopathic Addison's disease. Lancet 1968;ii:883-7.

Correspondence to Dr D B Grant. Hospital for Sick Children, Great Ormond Street, London WC1N 3JH

Received 25 March 1985 